\title{
A RAZÃO GEOMÉTRICA NA OBRA DE ALMIR MAVIGNIER: das artes visuais ao cartaz
}

\author{
Marko Alexandre Lisboa dos Santos \\ PPGDesign/FAAC/UNESP; FURB - Universidade Regional de Blumenau \\ malsantos@furb.br \\ Olimpio José Pinheiro \\ PPGDesign/FAAC/UNESP \\ olympio@faac.unesp.br
}

\begin{abstract}
Resumo: Este artigo, parte de uma pesquisa maior a nível de doutorado, tem como tema de investigação as Artes Visuais e o Design Gráfico de cartazes de Almir Mavignier. Particularmente, relata as análises realizadas sobre uma obra de arte e a posterior verificação das mesmas proposituras observadas em um cartaz realizado pelo artista. Ademais, tais análises pretendem demonstrar a possibilidade de articulação e proximidade entre conceitos advindos da arte construtiva e sua projeção no Design Gráfico.
\end{abstract}

Palavras-chave: design gráfico, cartazes, concretismo/neoconcretismo, Almir Mavignier

\begin{abstract}
This article, part of a larger study at the doctoral level, research has as its theme the Visual Arts and Graphic Design of posters Almir Mavignier. Particularly, reports the analyzes performed on the artwork and subsequent verification of those propositions observed on a poster by the artist. Moreover, such analyzes seek to demonstrate the possibility of joint and proximity between concepts under constructive art and its projection in Graphic Design.
\end{abstract}

Keywords: graphic design, posters, concretismo/neoconcretismo, Almir Mavignier.

\section{INTRODUÇÃO: ARTE, DESIGN, ALMIR MAVIGNIER}

Este artigo é um recorte de uma pesquisa de doutorado que aborda as relações entre o design e a arte, tomando-se o design de cartazes como eixo de observação. Objetivamente, trata da produção artística de Almir Mavignier e sua atuação como designer gráfico, no período contemporâneo ou posterior ao Neoconcretismo Brasileiro, no contexto das influências da Escola de Ulm (HfG - 
Hochschule für Gestaltung) e do cenário internacional, nomeadamente na Alemanha. Esta pesquisa analisa a produção em artes e em design gráfico para que, a partir delas, se observem os processos que levaram Mavignier a alcançar a forma gráfica com que desenvolveu seu trabalho. As relações com a atualidade se valem da sua produção de cartazes que o artista gráfico realiza na Alemanha, onde reside e estabelece um ateliê/estúdio. Pra lá destes objetivos neste artigo, buscamos os fatores de ligação que o design brasileiro tenha estabelecido com a Escola de Ulm (HfG), tendo Mavignier como referência, enquanto ex-aluno e posteriormente professor em Hamburgo (Hochschule für bildende Künste). Como decorrência, almeja-se que tais estudos possam proporcionar contribuições para o ensino, a pesquisa e a prática do design gráfico em nossos dias, mas também pretende-se resgatar a obra de um designer brasileiro de valor histórico inegável e relativamente pouco estudado entre nós.

\section{DESENVOLVIMENTO: REFERENCIAL TEÓRICO}

Inúmeras pesquisas e estudos têm sido realizados no que se refere à relação que o design estabelece com as artes visuais (Cf. FARIAS, 1999; CAUDURO, 2000; EGUCHI e PINHEIRO, 2008). Somente na edição do congresso Graphica, em 2013, foram publicados, pelo menos, cinco artigos referentes a pesquisas que estabelecem uma sintonia com estes temas (MENDONÇA; WANDERLEY; TRANJAN E MARTINS; SILVA, 2013) o que evidencia a importância das discussões com este enfoque e a devida preocupação em ampliar as pesquisas e as publicações neste sentido.

É sabido que mesmo antes das vanguardas modernistas do início do século XX e do advento da escola Bauhaus, as áreas das artes e do design estabelecem relações que vão além da influência formal de uma obra de arte em um produto de design (PINHEIRO, 1998). Essas inter-relações se dão, entre outros motivos, por conceitos que transcendem a representação formal e passam a estabelecer relações de um ponto de vista iconológico (PANOFSKY, 1986), no qual os produtos de design, influenciados pela arte, apresentam características inerentes aos respectivos movimentos artísticos.

É nesse contexto que adiante destacaremos o desenvolvimento da arte construtiva que culminou no Concretismo e Neoconcretismo brasileiro e, por conseguinte, no contexto inicial da formação artística de Almir Mavignier.

\section{1. $O$ contexto artístico na obra de Almir Mavignier}

Cabe salientar que o desenvolvimento do Design no Brasil esteve diretamente ligado à vertente artística abstracionista geométrica - o Concretismo - que ecoava há tempos na Europa, e que chegara a São Paulo em meados da década de 1950.

O Concretismo brasileiro configurou o segundo surto modernista brasileiro na década de 1950, se considerada como primeira manifestação a Semana de Arte de 1922. Com o Projeto Construtivo Brasileiro aflorou a modernidade das vanguardas europeias, hoje consideradas históricas ou primeiras vanguardas (TELES, 2000). Malevitch, os irmãos Gabo e Pevsner, Mondrian e posteriormente Max Bill, tornaramse, neste contexto, os principais pontos de referência (AMARAL, 1998).

A I Bienal de São Paulo, em 1951, agregou artistas de diversos movimentos da arte moderna do início do século XX, fato que concorreu para ampliar o interesse pela arte abstrata no país. Nesse evento, o suíço Max Bill, professor e diretor da Escola de 
Ulm (HfG), destacou-se ao receber o grande prêmio de escultura. Desde 1936, Bill utilizava o termo "arte concreta" para nomear sua arte, que, desprendendo-se da figuração, era construída privilegiando conceitos matemáticos (AMARAL, 1998).

Foi neste contexto histórico, segundo Amaral (op. cit), que em São Paulo se formou um grupo de artistas, composto por pintores e escultores, paulistas em sua maioria, denominado Grupo Ruptura. Contava, inicialmente, com Geraldo de Barros e Waldemar Cordeiro. Aos poucos, o grupo ampliou-se com a presença de Luiz Sacilotto, Anatol Wladyslaw, Lothar Charoux, Kazmer Féjer, Maurício Nogueira Lima, Alexandre Wollner, Hermelindo Fiaminghi, Antonio Maluf, Willys de Castro e Judith Lauand.

No Rio de Janeiro, constituiu-se um outro polo, que passou a se chamar de Grupo Frente. Reunia, em torno de Ivan Serpa, Almir Mavignier, Aluísio Carvão, Décio Vieira, João José da Silva Costa, Lygia Clark, Lygia Pape, Hélio Oiticica, Amilcar de Castro, Franz Weissman e Abraham Palatnik (GULLAR, 1999).

Tal como na Semana de 1922, os dois grupos agregaram poetas e artistas plásticos. Como poetas e críticos, os irmãos Augusto e Haroldo de Campos ao lado de Décio Pignatari participavam do grupo paulista. Do mesmo modo, Ferreira Gullar integrava o grupo do Rio.

Paulistas e cariocas estavam, a princípio, ligados pelos mesmos interesses. Manifestando-se contra a arte figurativa bem como contra o não figurativismo lírico expressionista que despontava no Brasil, buscavam uma maneira de voltar às formas puras da geometria para vivenciar uma nova visualidade. De certa forma, estavam alinhados com o conceito de arte concreta já visto na experiência de Max Bill.

Posteriormente, no Rio de Janeiro, o grupo Neoconcreto, fortemente embasado pela teoria do não-objeto formulada por Ferreira Gullar, passou a divergir em diversos pontos com os paulistas. Seus componentes consideravam o Concretismo um ponto de partida e não, um alvo. Desse modo, em rejeição às proposições do racionalismo concreto, desejavam expressividade para o vocabulário geométrico. Para isso, a intuição, a sensibilidade e a subjetividade não poderiam ser desprezadas.

Opondo-se à rigidez dos concretistas - favoráveis à integração arte/processos industriais - os neoconcretistas se voltaram para uma pesquisa diferenciada pelo intuitivo e o subjetivismo perceptual, seguindo principalmente as especulações fenomenológicas de Merleau-Ponty. A ênfase à experimentação na busca de soluções para um novo espaço expressivo apontava para "(...) uma direção explícita quanto à quebra de moldura e do espaço bidimensional da tela ou parede que evidenciava a lição aprendida com Malevitch, Tatlin, Gabo, Pevsner (...)” (NEVES, 1998, p. 99).

O Neoconcretismo, segundo Brito (1999), "representou a um só tempo o vértice da consciência construtiva no Brasil e sua explosão". E acentua: "o Neoconcretismo foi o último movimento plástico de tendência construtiva no país e que, inevitavelmente, encerrou um ciclo. Com ele termina o 'sonho construtivo' brasileiro como estratégia cultural organizada" (BRITO, 1999, p. 49).

Cabe aqui ressaltar neste contexto, que Almir Mavignier além de participar do grupo concretista carioca, veio a estudar na Escola Superior da Forma de Ulm (HfG Hochschule fur Gestaltung), de modo a estabelecer fortes laços com Max Bill que, 
possivelmente, influenciaram significativamente a sua produção, tanto na esfera das artes visuais como no design gráfico de cartazes.

\subsection{0 artista gráfico Almir Mavignier:}

Almir Mavignier nasceu em 1925, no Rio de Janeiro, iniciou-se na pintura em 1945 com Arpad Szenes, entre outros. Desenvolveu pesquisas como artista junto ao Grupo Frente e participou do Museu do Inconsciente entre os anos de 1946 a 1951. Em 1953 foi estudar na Alemanha, onde cursou a Escola Superior da Forma em Ulm (HfG - Hochschule für Gestaltung), de 1953 a 1958. Muda-se posteriormente para Hamburgo, onde passa a atuar como artista, designer e professor na Hochschule für Bildende Kunste, em Hamburgo, entre 1965 e 1990, onde vive até os dias atuais.

Foi durante a sua atuação no Hospital Psiquiátrico do Engenho de Dentro, donde sairiam as obras para o Museu do Inconsciente criado pela psiquiatra Dra. Nise da Silveira, que Mavignier estabeleceu relações com Ivan Serpa e Abraham Palatnik. Juntos, Serpa, Mavignier e Palatnik encontram Mário Pedrosa, crítico de arte, e começam a observar e discutir as tendências abstrato-geométricas que se iniciam em São Paulo e no Rio de Janeiro a partir de 1947.

Motivado pelas teorias da gestalt (vide: Da natureza da Forma na Obra de Arte, 1951), apresentadas por Mário Pedrosa (1979), Mavignier inicia pesquisas na área da abstração. Em 1949, participa do primeiro grupo de arte abstrata do Rio, com Ivan Serpa, Abraham Palatnik e Mário Pedrosa. Após a I Bienal de arte de São Paulo em 1950, o artista depara-se com a arte racional apresentada por Max Bill, que o motiva a embarcar para a Alemanha e estudar em Ulm, tal como Alexandre Wollner. Na Alemanha, entre 1953 e 1958, estuda com Max Bense e Josef Albers na HfG em Ulm, e mantém contato com Max Bill. Posteriormente passa a lecionar como professor na Hochschule für Bildende Kunste, em Hamburgo, Alemanha, entre 1965 e 1990.

Ainda que a carreira de Mavignier seja extensa, esta pesquisa pretende se focalizar em dois momentos significativos: a sua atuação junto aos movimentos concretistas nacionais, e a sua produção de cartazes que iniciou com a série "Aditivos" confeccionados na Alemanha.

Sua ida para Alemanha, entre outras coisas, se dá pela busca de respostas referentes aos questionamentos existentes para o artista acerca das relações entre a arte e o design, aqui evidenciadas pelas palavras do próprio artista:

\footnotetext{
"arte é design, pintura e cartaz são objetos, a pintura fascina e o cartaz informa. A fronteira entre ambos é instável porque ambos podem fascinar. A fim de reconhecê-la fui estudar em Ulm e aprendi que a fronteira não existe" (MAVIGNIER, 2000, p. 30).
}

Estas reflexões de Mavignier nos motivam a continuar nossos estudos de verificação e constatação da aproximação entre sua obra no campo das artes visuais e no design gráfico de seus cartazes.

\subsection{Metodologia de pesquisa:}

O tema abordado neste artigo valeu-se basicamente de pesquisas bibliográficas e históricas acerca da vanguarda abstracionista geométrica no Brasil, para daí recortar a atuação como artista visual e designer de Almir Mavignier. Este estudo apropriou-se 
não apenas de livros, teses e dissertações, mas também de artigos, imagens, internet, documentos diversos, entre outros.

São também analisadas obras artísticas concebidas por Mavignier, presentes em acervos como também disponíveis em livros e na internet. Além disso, são analisados cartazes por ele idealizados em sua fase pós-concretista.

Tanto as imagens das obras de arte - pinturas, gravuras (serigrafias) - como dos cartazes foram trabalhadas e analisadas por meio dos softwares AutoCad na versão 2012 e do CorelDraw X6.

\subsection{Análise da estrutura geométrica:}

O tratamento das análises e dos resultados se deu principalmente pelas relações estabelecidas nas artes e nos cartazes de Almir Mavignier. Uma vez identificada a intenção da racionalização em seu quadro, foi verificada essa intenção no processo de concepção de seu cartaz.

A obra apresentada neste artigo foi extraída do livro de Bonet (2010) e se chama Rotação Brasil, datada de 1992 e executada com a técnica de serigrafia sobre papel, com a dimensão de 59,4 x 84,1cm (cf. MAVIGNIER, 2013) (figura 1).

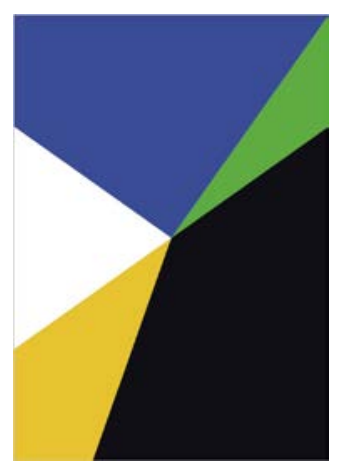

Figura 1 - Almir Mavignier. Rotação Brasil, 1992. Adaptada de Bonet (2010) p. 70.

Os recursos utilizados para as análises consistiram em um scanner - para capturar a imagem do livro -, do software CorelDraw para realizar o redesenho da obra em questão pelo motivo da obra escaneada perder qualidade e sofrer eventuais distorções características do processo de captura por este meio; além do software AutoCad, onde a imagem gerada pelo CorelDraw foi inserida para ter suas relações geométricas conferidas (figura 2).

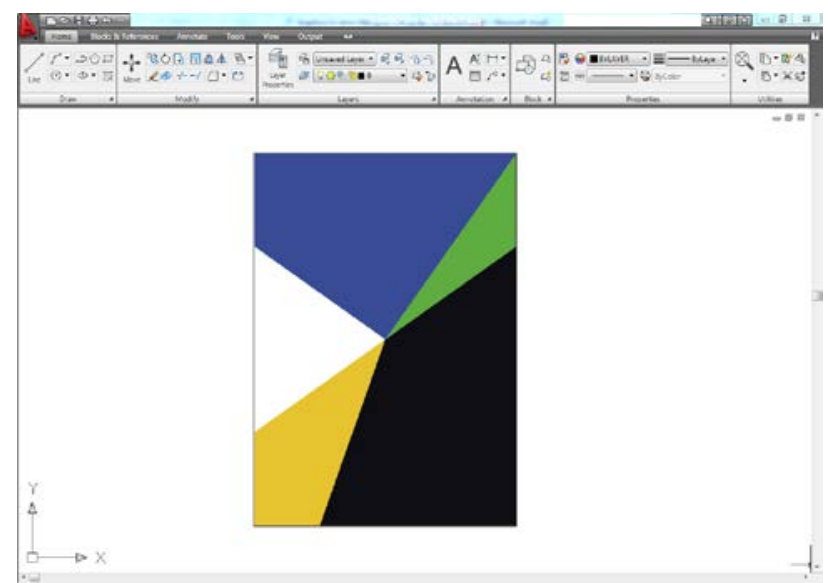

Figura 2 - A reprodução da obra inserida no AutoCad. 
O método de análise se deu pela construção de um desenho baseado na medida do quadro apontada pelo próprio Mavignier (2013) $-84,1 \times 59,5 \mathrm{~cm}$. Segundo o artista, a medida do quadro se deve a um tamanho de papel que estabelece esse formato como DIN - A1. A partir daí, foram traçadas retas definidas pelos pontos médios do retângulo; em seguida foi realizada mais uma divisão que resultaram numa malha retangular, conforme apontado por Samara (2008), um grid (figura 3).
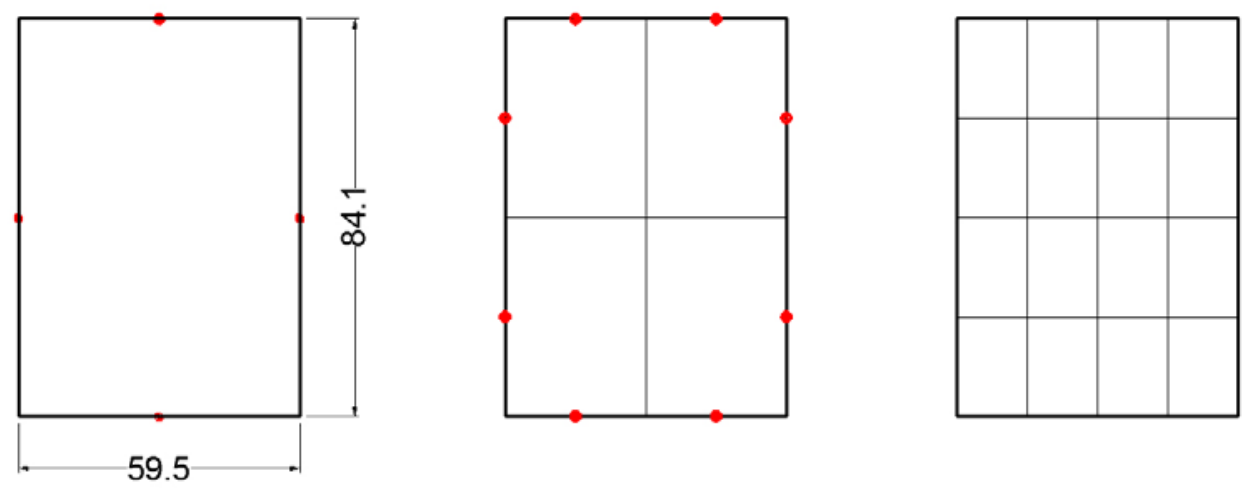

Figura 3 - 0 processo de divisão do quadro no AutoCad.

O próximo passo foi traçar retas a partir do centro do quadro em direção a determinados vértices ou pontos médios das laterais. Esse processo foi facilmente executado no software AutoCad devido os recursos e comandos de precisão que ele oferece, entre eles snap, osnap, orto, entre outros. Acompanhe na próxima figura:
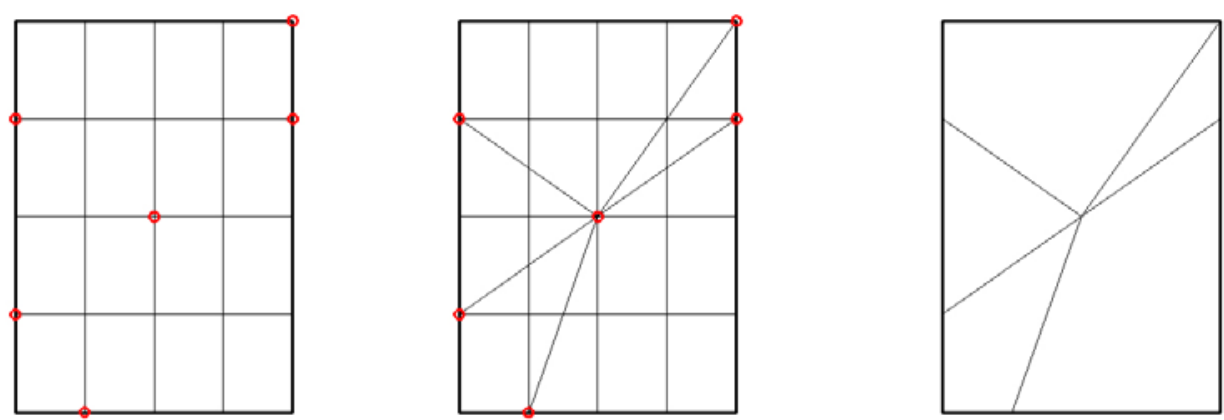

Figura 4 - As retas partem do centro em direção a pontos médios e vértices.

É possível estabelecer outras interpretações para a obtenção dessas retas que partem do centro do quadro: a primeira delas é que se utilizem ângulos para definir o direcionamento que essas retas poderiam ter, como pode ser observado na próxima figura: na imagem da esquerda observa-se os ângulos que definem a inclinação de cada linha. Outra possibilidade é que tais retas tenham sido concebidas ao serem traçadas as diagonais de retângulos menores, presentes na malha retangular (imagem central e da direita), observe: 

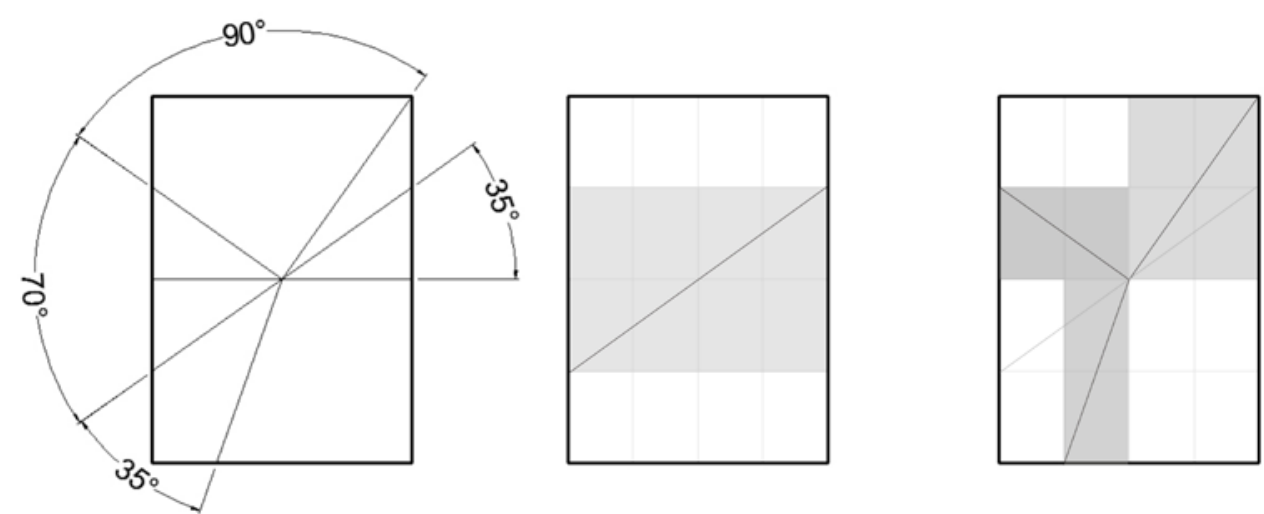

Figura 5 - As possibilidades de interpretação: por ângulos e por diagonais.

O quadro em questão foi idealizado em cinco versões (BONET, 2010). Tais versões foram obtidas por meio da rotação (ver mais em WEYL, 1997) das cores em cada um dos espaços, obedecendo a ordem em que aparecem na primeira imagem. Observe na próxima figura onde são apresentadas as versões do quadro e o sentido de rotação que as cores obedecem ao transitar de um espaço para o outro. Neste caso, foi destacada a cor azul com a numeração de 1 a 5 para efeito de compreensão.
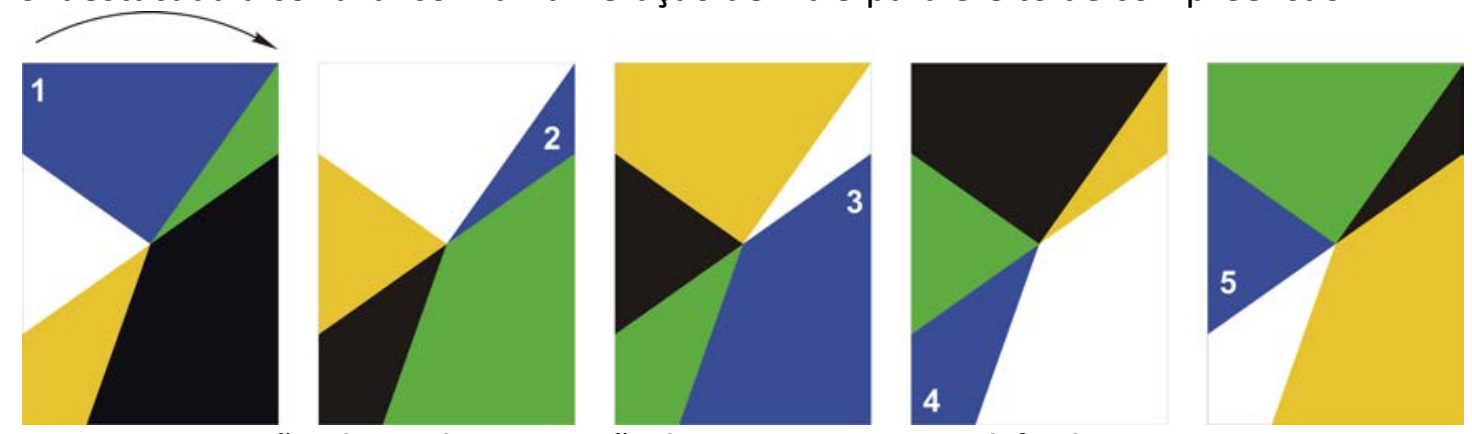

Figura 6 - As variações do quadro e transição das cores nos espaços definidos.

\subsection{Discussão estrutural:}

Observou-se durante as análises e confecção das figuras presente neste estudo que é possível que o artista tenha se utilizado dos recursos da malha retangular - ou grid - para a confeç̧ão do quadro. Essa consideração foi definida pelo fato de que os ângulos de $70^{\circ}$ assim como o de $35^{\circ}$ não são facilmente obtidos quando realizados manualmente. É necessário certo conhecimento com a utilização de esquadros ou mesmo um transferidor para se obter essa angulação de forma exata.

Contudo, conforme apontado anteriormente, no software AutoCad isso é realizado com certa facilidade pelo fato do usuário ter a opção de desenhar e traçar retas em determinados ângulos pré-definidos por meio do comando Polar traking.

Entende-se que o desenho confeccionado com base na malha retangular - grid - é mais facilmente obtido, uma vez que basta saber a dimensão total do quadro (tela ou suporte) para que, por meio dos pontos médios dos retângulos, sejam traçadas as retas que vão definir cada um dos espaços de cor do quadro.

Observou-se também, a partir do depoimento do próprio Mavignier, que a escolha do formato utilizado no quadro estabelece relação com o formato do papel utilizado na indústria gráfica. Entende-se nesse momento um estreitamento das proposituras construtivas do artista e sua relativa afinidade com conceitos da reprodução em larga escala - design gráfico. 
Além disso, foi possível constatar que a divisão do quadro por meio de razões geométricas possibilitou ao artista aumentar o poder de visualidade do seu trabalho. Ao realizar as mudanças de cor entre as áreas do quadro e posicionando-os lado a lado, o conjunto da obra alcançou novos significados, interpretações e relações que são explorados pelo artista na sua produção de cartazes (conforme discutido adiante).

As composições presentes na próxima figura evidenciam essa afirmação. Notase que a razão empregada na concepção da obra permitiu que uma cor se encaixasse lado a lado na outra de modo a inferir notória continuidade ao trabalho. Nessa situação apresentada adiante estão dispostas lado a lado cada uma das versões do quadro Rotação Brasil. Na primeira imagem as versões estão na posição original; na segunda imagem os quadros foram rotacionados em $180^{\circ}$.
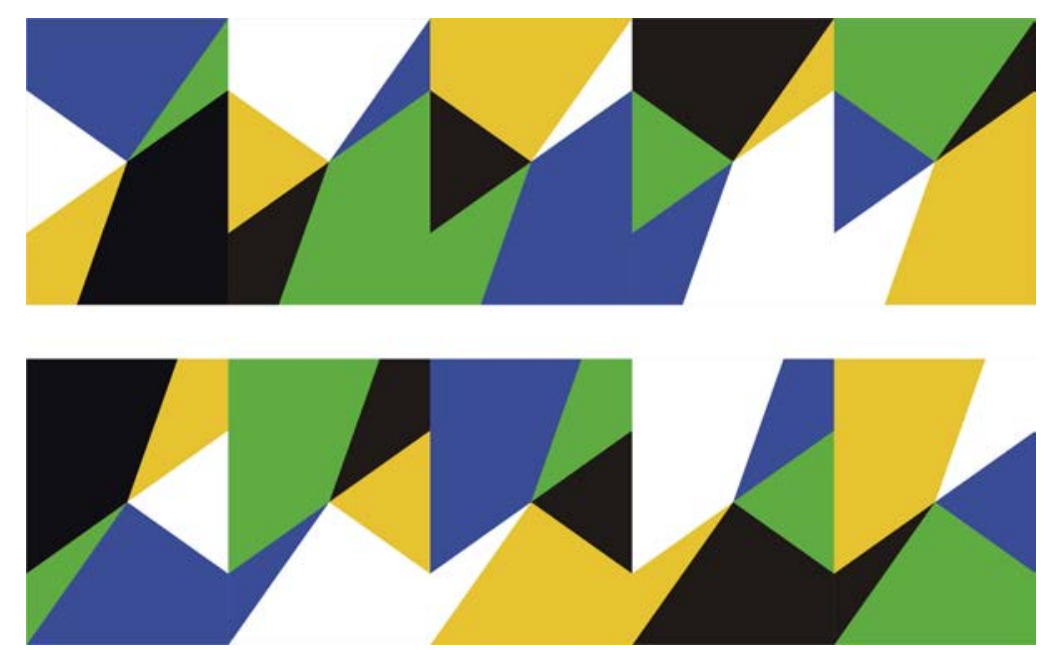

Figura 7 - Os quadros colocados lado a lado.

Na próxima figura, está evidenciada uma das possibilidades de justaposição das obras. Observe que a cópia de uma das versões do quadro foi rotacionada $180^{\circ}$ (a), de modo que ambas foram colocadas lado a lado (b). Após isso, a imagem foi transladada na direção horizontal (c) (WEYL, 1997), caracterizando uma verdadeira pavimentação do plano (d).

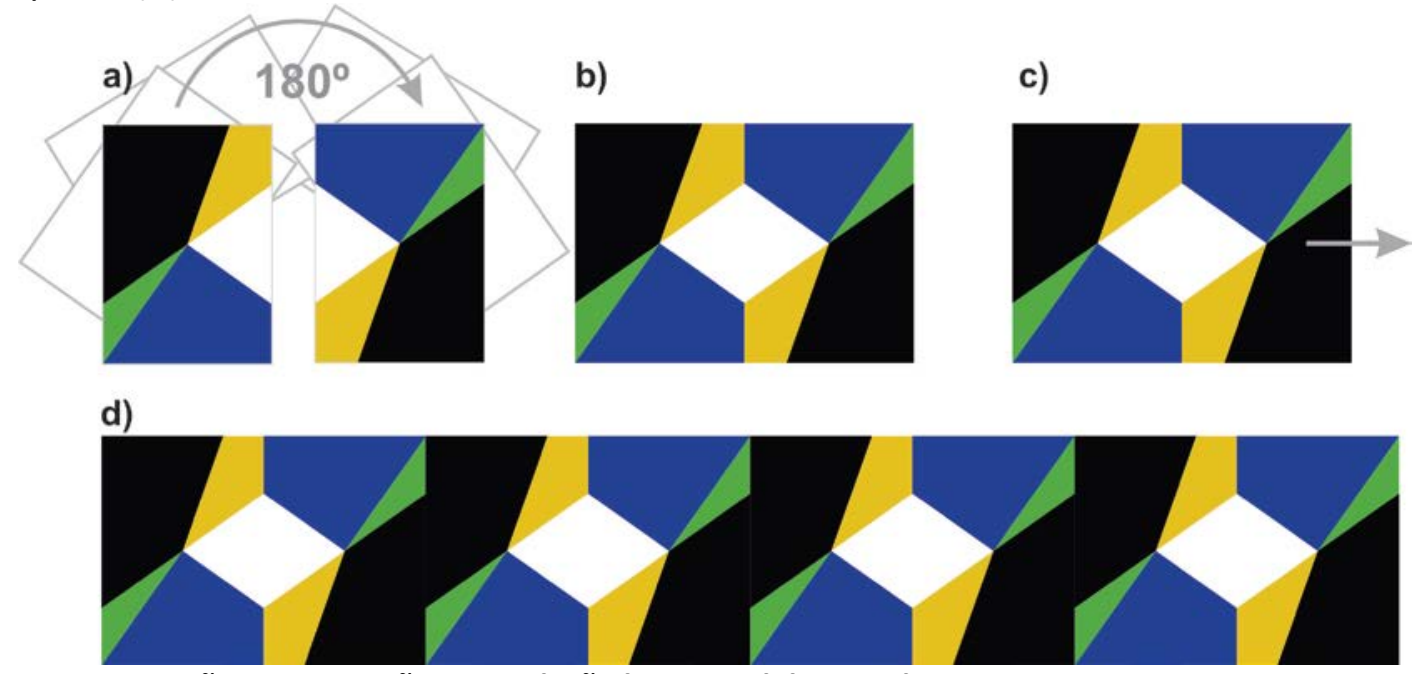

Figura 8 - Rotação, justaposição e translação horizontal dos quadros. 
$\mathrm{Na}$ imagem a seguir está representada a repetição dos quadros na direção vertical, evidenciando os pontos de conexão utilizados para conectar uma sequência de quadros à outra, aqui destacados pelas letras $x$ e $x^{\prime}$ (a). A figura $9 b$ representa $a$ pavimentação do plano resultante dessa repetição, onde estão destacadas na cor vermelha as formas resultantes da conexão de figuras de mesma cor que estão colocadas lado a lado. A figura 9c, representa tais figuras isoladas, evidenciando ainda as partes que se referem a cada um dos quadros.

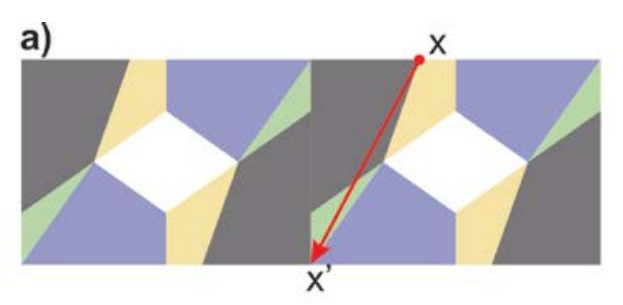

c)
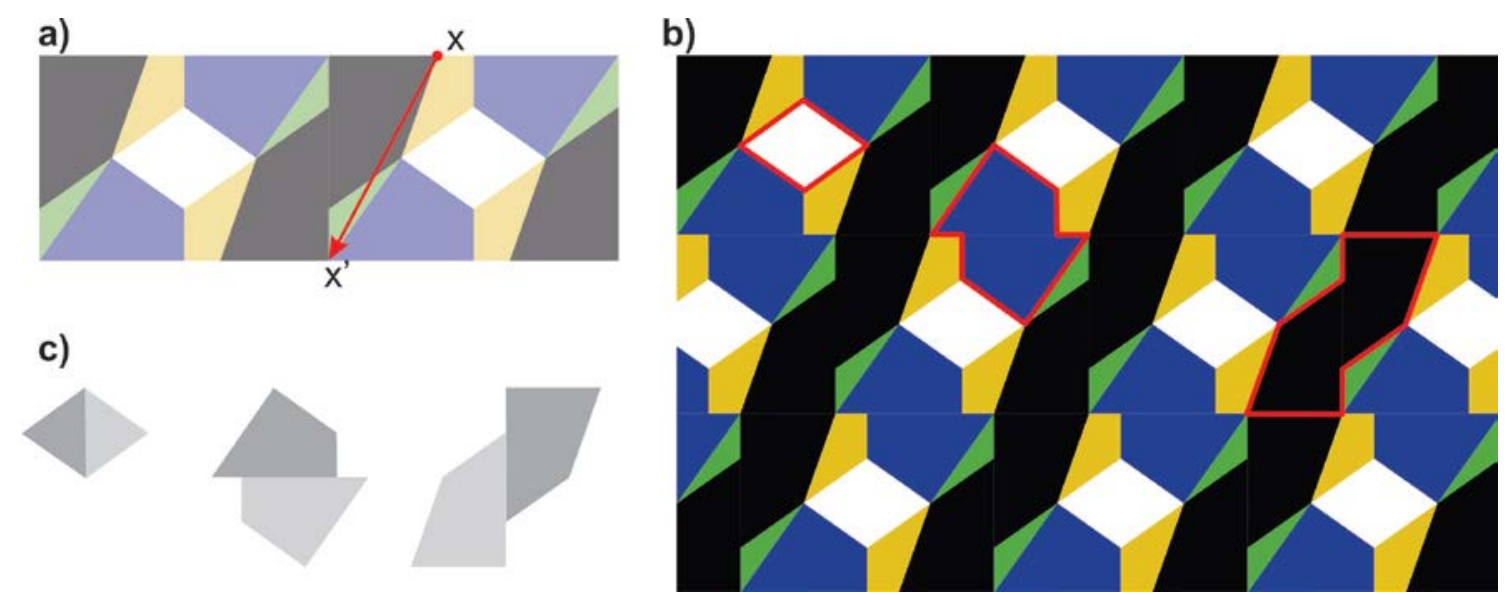

Figura 9 - Translação vertical dos quadros e as formas de conexão.

As próximas análises se deram para verificar se o mesmo raciocínio empregado na confecção da série de quadros Rotação Brasil seriam identificados em cartazes idealizados por Almir Mavignier. Dessa forma, foi selecionado o cartaz apresentado na figura 10, conforme se segue:
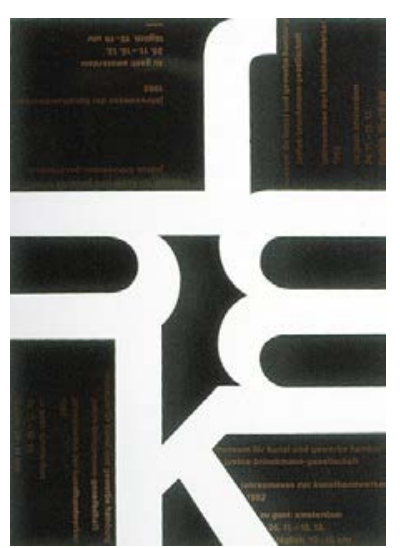

Figura 10 - Cartaz sem título de Almir Mavignier, 1982.

Desse modo, na primeira análise realizada a imagem do cartaz foi repetida e transladada de maneira simples, na horizontal e vertical, observe. 
a)

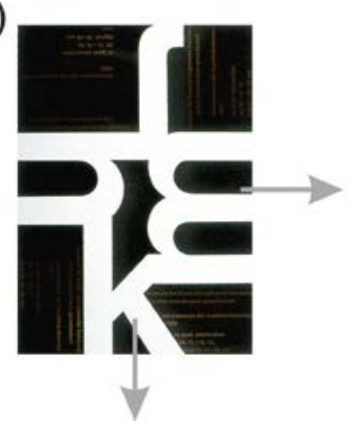

b)

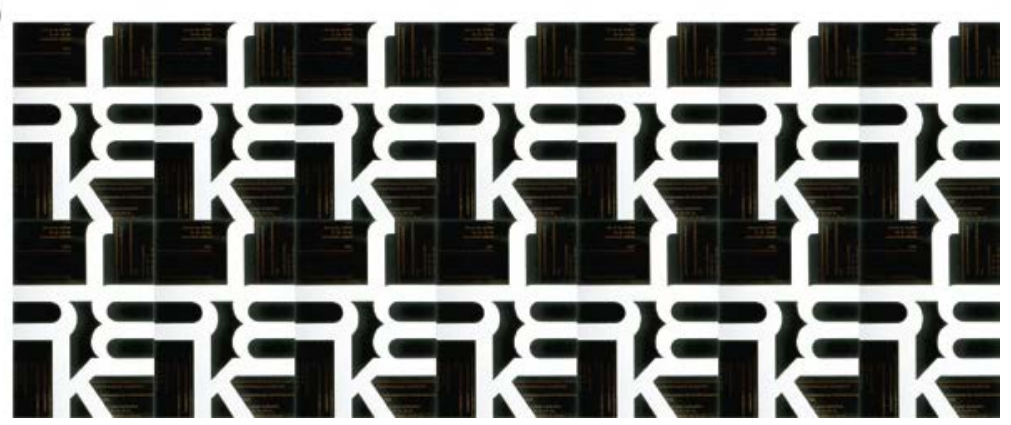

Figura 11 - Rotação, justaposição e translação dos quadros.

Embora o posicionamento das imagens sejam simples, já denotam forte tendência de elementos de conexão entre um cartaz e outro.

A próxima figura apresenta a análise em que o cartaz foi rotacionado $180^{\circ}$ (12a) e posicionado lado a lado (12b), após isso esse conjunto de dois cartazes foi transladado no sentido horizontal e vertical (12c) semelhante ao realizado em Rotação Brasil. O resultado foi uma pavimentação do plano diferente daquela obtida e representada na figura 11.
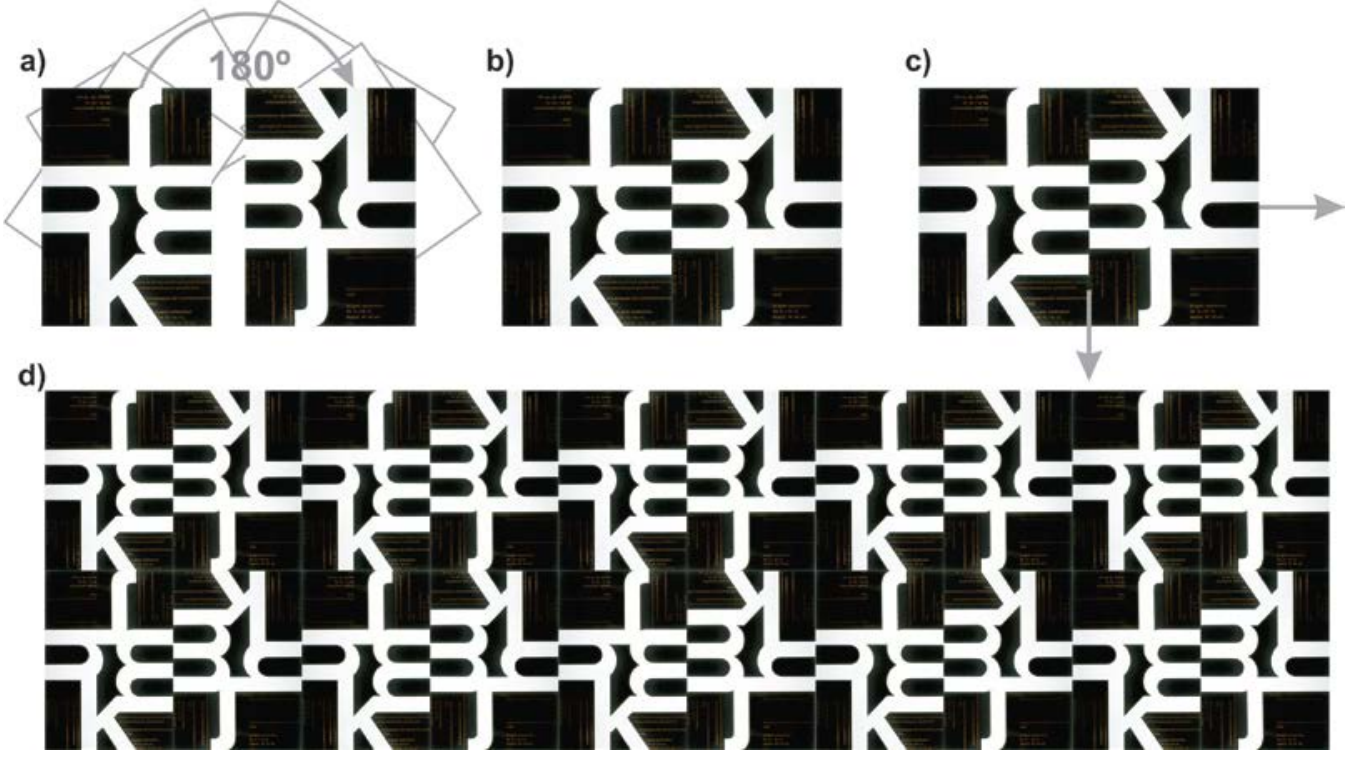

Figura 12 - Rotação, justaposição e translação dos quadros.

Continuando com as análises, a seguir são destacadas na cor vermelha as figuras que se formam com as áreas de conexão entre um cartaz e outro, o que denota uma grande similaridade de conceito e de intenção de pavimentação do plano, do mesmo modo que foi observado em Rotação Brasil, observe:

a)

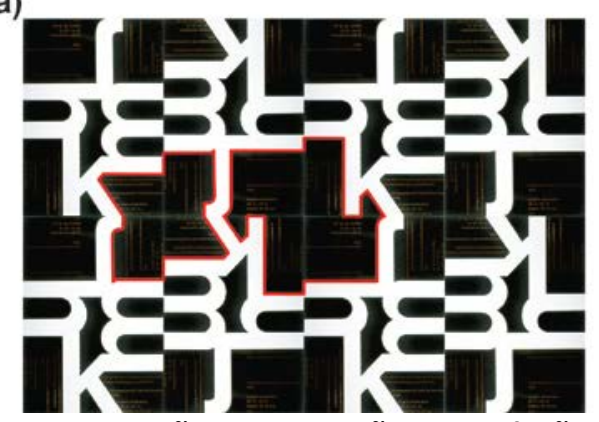

b)
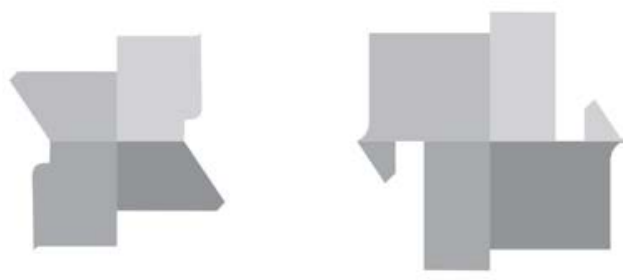

Figura 13 - Rotação, justaposição e translação dos quadros. 


\section{CONSIDERAÇÕES PROVISÓRIAS:}

O estudo aqui apresentado evidencia a proximidade entre a arte e o design gráfico de Almir Mavignier; na produção artística também podemos observar o projeto que tende à serialização, embora seja um conceito mais frequente no design.

Observa-se que a linguagem geométrica é facilmente explorada com conceitos básicos de geometria como divisão de áreas, diagonais, ponto médio, centro, simetrias, entre outros. Essa evidência é válida para que o designer possa explorar tais conceitos, não só para a representação gráfica, mas também para a geração de ideias nos momentos iniciais do projeto e na continuidade do mesmo.

Convém destacar que Mavignier manifestou sua arte alinhada às características da arte concreta, fazendo uso de sua sensibilidade para propor construções que o levaram a alcançar formas significativas que ficaram ainda mais destacadas com a utilização de cores e os encaixes resultantes da pavimentação do plano.

As considerações aqui evidenciadas confirmam a importância da obra de Almir Mavignier e, sobretudo, sua importância para a consolidação das Artes e do Design nacional. Vale lembrar, mais uma vez, que o estudo completo acerca dos cartazes aditivos e justapostos de Almir Mavignier fazem parte da pesquisa de doutorado de um dos autores.

A presente contribuição é um estímulo para o desenvolvimento de trabalhos posteriores que busquem o resgate e o aprofundamento da vida e obra de Almir Mavignier. Esperamos que todos estes estudos possam trazer novas contribuições para as experimentações no campo do design gráfico, assim como para a história da arte e do design brasileiro.

\section{REFERÊNCIAS}

AMARAL, Aracy (org.). Arte Construtiva no Brasil. São Paulo: Companhia Melhoramentos; São Paulo: DBA Artes Gráficas, 1998.

BONET, J. M. 60 anos de arte construtiva no Brasil. 1a ed. São Paulo: Dan Galeria, 2010.

BRITO, Ronaldo. Neoconcretismo: vértice e ruptura do projeto construtivo brasileiro. São Paulo: Cosac Naify, 1999.

CAUDURO, Flávio Vinícius. Design gráfico \& pós-modernidade. Revista FAMECOS. Porto Alegre, no 13, p. 127 - 139. Dez, 2000.

EGUCHI, H. C.; PINHEIRO, Olympio. Design versus artesanato: identidades e contrastes. In: Anais do 8 o Congresso Brasileiro de Pesquisa \& Desenvolvimento em Design. São Paulo: AEND, Brasil, 2008. p. 1673-1679.

FARIAS, Agnaldo. Design é arte?. Boletim ADG - Associação dos Designers Gráficos, № 18, dez. 1999, p. 25-32.

GULLAR, Ferreira. Etapas da arte contemporânea: do cubismo à arte neoconcreta. 3a ed. Rio de Janeiro: Renavan, 1999.

MAVIGNIER, Almir. Mavignier 75. São Paulo: MAM, 2000. (Tradução Andréa Fairman; Apresentação Milú Villela; Introdução Aracy Amaral). 
MAVIGNIER, Almir. Re: contato mavignier [mensagem pessoal]. Mensagem recebida por Marko Santos (kakosantos@gmail.com), em 26 abril 2013.

MENDONÇA, A. N. F. de. Design e Expressão Gráfica na Arte de Rafael Sanzio. In: XXI Simpósio Nacional de Geometria Descritiva e Desenho Técnico. X International Conference on Graphics Engineering for Arts and Design, 2013. Anais do Graphica 2013. Expressão Gráfica: Tecnologia e Arte para Inovação. Departamento de Expressão Gráfica - UFSC. Florianópolis: Editora CCE - UFSC, 2013.

NEVES, A. F. Em busca de uma vivência geométrica mais significativa. Tese (doutorado) - Unesp. Faculdade de Filosofia e Ciências. Marília, 1998. 225 p.

PANOFSKY, Erwin. Estudos de iconologia. Lisboa: Editorial Estampa. 1986.

PEDROSA, Mário. Arte, Forma e Personalidade; 3 estudos. São Paulo: Kairós, 1979.

PINHEIRO, Olympio. Imagem, Miragem, Imagem de Síntese. Revista da UFP, Porto, Portugal, v. 1, n.2, p. 161-180, 1998.

SAMARA, Timothy. Grid: construção e desconstrução. São Paulo: Cosac Naify, 2008

SILVA, C. M. N. O traço geométrico no ensino e execução da arte: um olhar sobre Leonardo da Vinci. In: XXI Simpósio Nacional de Geometria Descritiva e Desenho Técnico. X International Conference on Graphics Engineering for Arts and Design, 2013. Anais do Graphica 2013. Expressão Gráfica: Tecnologia e Arte para Inovação. Departamento de Expressão Gráfica - UFSC. Florianópolis: Editora CCE - UFSC, 2013.

TELES, G. M. Vanguarda europeia e Modernismo brasileiro: Apresentação dos principais poemas, manifestos, prefácios e conferências vanguardistas, de 1857 a 1972. 16a . ed. Petrópolis: Vozes, 2000.

TRANJAN, C. G.; MARTINS, M. C. A. Lygia Pape e a união entre a arte e o design: a marca Piraquê. In: XXI Simpósio Nacional de Geometria Descritiva e Desenho Técnico. $X$ International Conference on Graphics Engineering for Arts and Design, 2013. Anais do Graphica 2013. Expressão Gráfica: Tecnologia e Arte para Inovação. Departamento de Expressão Gráfica - UFSC. Florianópolis: Editora CCE - UFSC, 2013.

WANDERLEY,R. G.; Nascimento, R. A. do; NEVES, A. F. A geometria e o estudo da forma envolvidos nos desenhos bases da renda renascença. In: XXI Simpósio Nacional de Geometria Descritiva e Desenho Técnico. X International Conference on Graphics Engineering for Arts and Design, 2013. Anais do Graphica 2013. Expressão Gráfica: Tecnologia e Arte para Inovação. Departamento de Expressão Gráfica - UFSC. Florianópolis: Editora CCE - UFSC, 2013.

WEYL, H. Simetria. São Paulo: Edusp, 1997. 